\title{
PARADIGMS OF LIVER TRANSPLANTATION FOR HEPATOCELLULAR CARCINOMA IN THE REPUBLIC OF BELARUS
}

Poster presented at Forum for Interdisciplinary Research in Medicine, Science \& Technology Conference, Moscow 2020

Peer reviewed by JS Bamrah, Ananthakrishnan Raghuraman, Soumit Dasgupta \& Jyothi Srinivasan

\section{Aim:}

To evaluate the effectiveness of the liver transplantation of patients with Hepatocellular carcinoma ( $\mathrm{HCC}$ ) and cirrhosis according to morphological (Milan criteria) and oncological criteria.

Keywords

liver transplantation; hepatocellular carcinoma
Denis Efimov; Aliakesei Shcherba; Sergei Korotkov; Oleg Rummo

Minsk Scientific and Practical Center of Surgery, Transplantology and Hematology, Minsk, Belarus

Correspondence to den.efimoff@gmail.com

Cite as: Efimov, D., Shcherba, A., Korotkov, S., \& Rummo, O. (2020) PARADIGMS OF LIVER TRANSPLANTATION FOR HEPATOCELLULAR CARCINOMA IN THE REPUBLIC OF BELARUS. The Physician vol 6; issue 3; epub 04 Aug 2020; DOI: https://doi.org/10.38192/1.6.3.firmst20.ab44

\section{Article Information}

Published 01 Oct 2020

Open Access - Creative Commons Licence CC-BYND-4.0

\section{Introduction:}

In spite of the number of medical technologies developed in the world for the treatment of HCC, the most acute question at the moment is the selection criteria for such for liver transplantation, the place and time of application of other methods of treatment to achieve optimal long-term results.

\section{Materials:}

A retrospective cohort study of patients undergoing liver transplantation from 2008 to 2019 (a total of 690 transplantations, 105 (15\%) of recipients with $\mathrm{HCC}$ ) in the Minsk Scientific and Practical Center for Surgery, Transplantology and Hematology (Minsk, Republic of Belarus) was performed. The patients were divided into 3 groups: (1) recipients whose liver transplantation was performed according to the Milan criteria ("Milan"), (2) recipients that did not meet neither the Milan criteria nor the University of California in San Francisco (UCSF) criteria ("extraUCSF") and (3) recipients that did not meet the Milan and UCSF criteria that meet the Barcelona clinic liver cancer (BCLC) staging (BCLC-B) criterion and undergo locoregional therapy (LRT) with subsequent assessment of the radiological and serological response ("Lerut"). In each group, the frequency of progression in the waiting list and the recurrence rate of HCC after transplantation, hospital mortality, the frequency of arterial and biliary complications, and cancer-associated mortality were assessed.

\section{Results:}

The highest rate of $\mathrm{HCC}$ progression on the waiting list was observed in the extra-UCSF group of patients (36\% versus $11 \%(p=0.03)$ and $15 \%(p=0.1)$ in the "Milan" and "Lerut" groups, respectively). Statistically significant differences were found in the level of cancer-associated mortality and median disease-free survival, with the worst rates in the extra-UCSF group. The one-year, three- 
year and five-year overall survival rate in the groups were $87.5 \% ; 80.1 \%$ and $70.3 \%$ for the Milan group; $78.6 \%$; $62.9 \%$ and $62.9 \%$ for the extra-UCSF group and $96.4 \%$; $86.4 \%$ and $78.7 \%$ for the Lerut group, respectively.

\section{Conclusion:}

The oncological prognosis of patients with HCC is informed not only from the size and number of tumour foci as from the biological characteristics of the tumour.
LRT combines both a therapeutic option, that allows reach better survival, and a stratification option, that enable patients to wait for liver transplantation beyond the accepted criteria.

Conflict of Interests/Comments:

Nothing to declare. 